\title{
PENYUSUNAN KRITERIA DOMESTIKASI DAN EVALUASI PRAKTEK PENGASUHAN GAJAH: STUDI DI TAMAN NASIONAL WAY KAMBAS KABUPATEN LAMPUNG TIMUR
}

\section{(DEVELOPING DOMESTICATION CRITERIA AND EVALUATION FOR THE ELEPHANT NURTURING PRACTICE: CASE STUDY AT WAY KAMBAS NATIONAL PARK OF EAST LAMPUNG-INDONESIA)}

\author{
Putri Meytasari, Samsul Bakri dan Susni Herwanti \\ Jurusan Kehutanan Fakultas Pertanian Universitas Lampung \\ Jl. Soemantri Brojonegoro No. 1 Bandar Lampung \\ Email : Putrimeytasari@ rocketmail.com Nomor telepon : 08537908664
}

\begin{abstract}
ABSTRAK
Gajah Sumatera (Elephas maximus sumatranus) merupakan salah satu satwa liar yang telah banyak didomestikasi, tetapi sejauh ini belum tersedia kriteria domestikasi dari kehidupan liar satwa ini. Untuk itu pada tahap pertama penelitian ini dilakukan penyusunan kriteria domestikasi. Hasil ini selanjutnya digunakan untuk melakukan evaluasi praktek pengasuhan gajah Sumatera jinak di Pusat Konservasi Gajah (PKG) dan di Elephant Respon Unit (ERU) Taman Nasional Way Kambas. Penelitian ini dimulai bulan April sampai dengan Mei 2013. Ada 17 variabel yang digunakan, masing-masing dikelaskan kedalam tiga katagori, yaitu Sesuai; Kurang Sesuai; dan Tidak Sesuai bagi lingkungan domestikasi gajah. Batas-batas nilai kagatori Sesuai ditetapkan melalui studi pustaka terhadap hasil-hasil riset. Sedangkan katagori Kurang Seusai disimpangkan (diturunkan ataupun dinaikan) sebesar 25\% dari batasbatas katagori Sesuai, selanjutnya disimpangkan lagi sebesar 25\% untuk katagori Tidak Sesuai. Validasi terhadap ketiga katagori dilakukan dengan menggunakan Metode Delphi kepada para pemerhati gajah sebagai validator. Hasil penelitian ini adalah (1) Telah diperoleh susunan kriteria yang dapat digunakan sebagai rubrik penilaian dalam domestikasi gajah Sumatera yang dipandang valid oleh para pemerhati gajah, dan (2) Praktek pengasuhan gajah jinak di PKG dan ERU secara agregat dapat dipandang Sesuai, kecuali untuk variabel populasi berkelompok, home range dan naungan bagi gajah.
\end{abstract}

Kata kunci : kriteria domestikasi, gajah Sumatera, praktek pengasuhan gajah

\section{ABSTRACT}

Sumatran elephants (Elephas maximus sumatranus) is one of the many wild animals been domesticated, but so far there is no criteria for that propose. This research is a prelimenary effort in providing those criteria. This research began in April to May 2013. The first step was to establish the norm of Suitable range of as many as 17 variables required for upholding the elephant life domestication area. The Suitable norm range we determined through an exhausted study of previous researchs or literature available. The next step was to determined the Less Suitable and the Not Suitable norms range for those 17 variables employed, e.i. by deviating by $25 \%$ and by $50 \%$ from the Suitable norm range respectively. The second step, we employed a Delphi Method in order to validate and refinary the three catagorical norms range of the 17 varibles concerned by mean of asking to some elaphant experts in our country. We, then applied the deemed criteria to evaluate a practice of ephants management at The Sumatra Elephant Conservation Center (PKG) and the Elephant Response Unit (ERU), Way Kambas National Park. The research results: (1) We obtained 
the prelimenary criteria as a rubric for Sumatran elephant domestication, and (2) The elephant nurturing practices at PKG and ERU were Suitable, except for the variables of population density, home range and elephant shading.

Keywords : domestication criteria, sumatran elephant, practices of elephant nurturing

\section{PENDAHULUAN}

Gajah Sumatera (Elephas maximus sumatranus) merupakan salah satu kekayaan fauna Indonesia yang termasuk satwa langka dan dikhawatirkan akan punah. Satwa ini telah dilindungi sejak 1931 menggunakan Ordonansi Perlindungan Binatang Liar Nomor 134 dan 226 dan diperkuat SK Menteri Pertanian RI No. 234/Kpts/Um/1972 dan Peraturan Pemerintah Republik Indonesia No. 7 Tahun 1999 tentang Pengawetan Jenis Tumbuhan dan Satwa. Sementara itu CITES (Convention on International Trade in Endangered Species of Wild Flora and Fauna) menggolongkan gajah dalam daftar Appendix 1 yang merupakan satwa liar yang tidak boleh diperdagangkan secara international baik gading dan bagian tubuh lainnya (CITES, 2000).

Menurut Alikodra (2002) satwa liar mempunyai peranan yang sangat penting bagi kehidupan manusia, baik untuk kepentingan keseimbangan ekosistem, ekonomi, maupun sosial budaya. Dalam keseimbangan ekosistem, gajah mempunyai peranan antara lain sebagai agen penyebaran biji tumbuhan dan pengendali pertumbuhan flora. Gajah juga memiliki peran penting sebagai penunjang pengendalian konflik gajah liar yang sering kali juga digunakan untuk kepentingan ekonomi seperti objek wisata. Gajah banyak dimanfaatkan sebagai daya tarik wisata seperti di kebun binatang, taman safari, taman marga satwa maupun taman nasional tidak terkecuali di Taman Nasional Way Kambas (TNWK).

Gajah Sumatera yang berada di Pusat Konservasi Gajah (PKG) atau pun Elephant Respon Unit (ERU) adalah hasil domestikasi dari TNWK sejak tahun 1985 saat berdirinya PKG. Program domestikasi satwa liar khususnya gajah dapat digunakan tujuan ganda, yaitu disamping untuk memenuhi kebutuhan masyarakat (orientasi sosial ekonomi, budaya, rekreasi) juga sekaligus untuk menopong kelestarian spesies tersebut (Alikodra, 2010). Gajah jinak hasil domestikasi kemudian mendapat pengasuhan dari mahout, orang yang bertugas untuk merawat dan melatih gajah.

Salah satu aktivitas Taman Nasional Way Kambas antara lain melakukan pembinaan anak gajah, yaitu anak-anak gajah yang berasal dari gajah domestikasi tetap jinak sedangkan yang berasal dari gajah liar turut menjadi jinak. Gajah liar yang turut menjadi pelaku pengrusakan lahan pertanian masyarakat dapat diminimalisir jumlahnya dengan gajah jinak dan gajah jinak juga dapat dimanfaatkan sebagai penunjang ekowisata di PKG maupun ERU (Firqan, 2012).

Menurut Stremme (2007) Manager Pengawasan Kesehatan Gajah Veterinary Society for Sumatera Wildlife Conservation (VESSWIC) yang membantu mengawasi kesehatan gajahgajah di TNWK mengatakan, bahwa kondisi lingkungan dan ketersediaan pakan kurang memenuhi persyaratan minimal bagi praktek domestikasi gajah, kegiatan domestikasi (yang mendukung kegiatan konservasi), karena pengelola TNWK belum menyediakan pakan tambahan seperti pisang, beras merah, dan vitamin selain pakan utama yaitu rumput yang memadai, Selain itu gajah seharusnya mendapat pengobatan dan pemeriksaan kesehatan minimal tiga sampai empat kali setahun, agar terhindar dari penyakit kecacingaan atau pun penyakit parasit lainnya. Sebaiknya general check up juga dilakukan dengan frekuensi tersebut. Namun karena keterbatasan dana, pemeriksaan dan pemberian obat serta pemberian pakan tambahan sulit dilakukan (Nababan, 2007). 
Menurut pendapat Stremme (2007) diatas didukung juga oleh Shoshani dan Eisenberg (1982), persyaratan minimal lingkungan hidup bagi gajah Sumatera untuk hidup di alam meliputi: naungan yang berfungsi untuk menyetabilkan suhu tubuhnya agar sesuai dengan lingkungannya. Selain itu, gajah membutuhkan makanan yang terdiri dari bagian-bagian tumbuhan hijau yang cukup di habitatnya sebagai makanan pelengkap dalam memenuhi kebutuhan mineral kalsium. Gajah juga memerlukan asupan nutrisi air dan garam mineral seperti: kalsium, magnesium dan kalium. Gajah membutuhkan ruang atau wilayah jelajah (home range) yang luas serta memerlukan keamanan dan kenyamanan agar prilaku kawin (breeding) tidak terganggu.

Program domestikasi gajah seharusnya memperhatikan syarat minimal gajah di alam. Pedoman pengasuhan gajah jinak dalam lingkungan domestikasi belum ada kriteria secara tertulis sehingga perlu dilakukan penelitian dengan tujuan menyusun kriteria penilaian syarat-syarat lingkungan untuk domestikasi gajah Sumatera yang akan divalidasi oleh pemerhati gajah dan melakukan evaluasi praktek pengasuhan gajah Sumatera jinak di TNWK.

\section{METODE PENELITIAN}

Penelitian dilaksanakan di PKG dan ERU TNWK Lampung Timur pada bulan April sampai dengan Mei 2013. Alat yang digunakan dalam penelitian adalah alat tulis, komputer, kamera, peta lokasi dan kuesioner. Obyek dalam penelitian ini adalah praktek pengasuhan gajah Sumatera PKG dan ERU di TNWK. Data yang digunakan dalam penelitian terdiri dari data primer dan data sekunder.

Data yang dikumpulkan dari berbagai studi pustaka dengan cara mencari, mengumpulkan, dan menganalisis data penunjang yang terdapat dalam dokumen resmi seperti buku-buku, skripsi, dan literatur lainnya yang dipakai sebagai bahan referensi. Data kemudian ditabulasikan kedalam bentuk tabel atau rubrik kriteria pengasuhan gajah di lingkungan domestikasi. Ada 17 variabel yang digunakan, masing-masing dikelaskan kedalam tiga kategori, yaitu sesuai; kurang sesuai; dan tidak sesuai bagi lingkungan domestikasi gajah. Batas-batas nilai kategori sesuai ditetapkan melalui studi pustaka terhadap hasil-hasil riset. Sedangkan kategori kurang seusai disimpangkan (diturunkan ataupun dinaikan) sebesar $25 \%$ dari batas-batas kategori sesuai, selanjutnya disimpangkan lagi sebesar 25\% untuk kategori tidak sesuai.

Validasi kriteria pengasuhan gajah di lingkungan domestikasi dilakukan oleh pemerhati gajah dengan menggunakan metode delphi. Metode delphi adalah suatu proses kelompok yang digunakan untuk memperoleh tanggapan tertulis dari beberapa individu, yang dimaksudkan untuk mengumpulkan pendapat dari sejumlah individu dalam rangka meningkatkan mutu pengambilan keputusan (Syafruddin, 2010). Kemudian divalidasi oleh pemerhati gajah sehingga tabel bisa digunakan untuk evaluasi pengasuhan gajah di PKG dan ERU.

Pengambilan sampel evaluasi praktek pengasuhan gajah dalam penelitian ini dilakukan dengan menggunakan metode snowball sampling. Snowball sampling merupakan teknik pengambilan sampel yang akan berhenti prosesnya jika jawaban yang diterima sudah dapat menjawab semua pertanyaan dan dapat medukung pencapaian tujuan penelitian (Sugiyono, 2009). Analisis hasil yang dilakukan dalam pengolahan data dibagi dalam tiga kategori yaitu sesuai, kurang sesuai dan tidak sesuai. Berdasarkan Nasution (2012) penghimpunan skor dapat dilakukan dengan menggunakan skala Linkert yang terdiri dari pertanyaan dengan jawaban sesuai (diberi skor 3), kurang sesuai (diberi skor 2) dan tidak sesuai (diberi skor 1).

Penentuan kategori digunakan interval kelas dengan rumus sebagai berikut (Yitnosumarto, 1994) : 


$$
I=\frac{X_{1}-X_{2}}{K}
$$

Keterangan :

$\mathrm{I} \quad=$ Interval

$\mathrm{X}_{1} \quad=$ Nilai pengamatan tertinggi

$\mathrm{X}_{2} \quad=$ Nilai pengamatan terendah

$\mathrm{K}=$ Jumlah kategori

Skor jawaban kemudian dihimpun dalam tabel pengembangan kriteria domestikasi dan pengasuhan gajah Sumatera. Aspek pengasuhan gajah Sumatera berjumlah 17 pertanyaan berdasarkan jumlah variabel kriteria pengasuhan gajah Sumatera yang sudah tervalidasi dari pemerhati gajah sehingga memiliki skor tertinggi 51 dan skor terendah 17. Parameter dalam pengasuhan gajah Sumatera yaitu: kategori sesuai diberi skor antara 40--51, kategori kurang sesuai diberi skor 29--39 dan kategori tidak sesuai diberi skor 17--28.

Data yang diperoleh disajikan dalam bentuk tabel untuk mengetahui pengembangan kriteria domestikasi gajah Sumatera dan keberhasilan pengasuhan gajah jinak di PKG dan ERU TNWK. Selanjutnya jika diperlukan data yang diperoleh dapat dijadikan dasar untuk meningkatkan manajemen pengasuhan gajah jinak yang diterapkan.

\section{HASIL DAN PEMBAHASAN}

Secara geografis Taman Nasional Way Kambas (TNWK) terletak antara $40^{\circ} 37^{\prime}-$ $50^{\circ} 16^{\prime}$ LS dan antara $105^{\circ} 33^{\prime}--105^{\circ} 54^{\prime}$ BT. Berada di bagian tenggara pulau Sumatera di wilayah Propinsi Lampung. Sebagian besar merupakan perwakilan ekosistem hutan dataran rendah yang terdiri dari hutan rawa air tawar, padang alang-alang atau semak belukar, dan hutan pantai di Sumatera. Sebagian besar merupakan dataran rendah yang sedikit bergelombang dengan ketinggian yang bervariasi dari 0--60 mdpl. Memilki curah hujan 4000 $\mathrm{mm}--5000 \mathrm{~mm}$ pertahun dan memilki temperatur udara antara $28^{\circ}--37^{\circ} \mathrm{C}$. Pola daerah aliran sungai yang terdapat pada sekitar kawasan TNWK.

Taman Nasional Way Kambas (TNWK) ditetapkannya sebagai kawasan pelestarian alam adalah untuk melindungi kawasan yang kaya akan berbagai satwa liar salah satunya gajah Sumatera. Untuk bertahan hidup gajah memiliki syarat minimal yaitu ketersediaan air untuk mandi, minum, dan berkubang, garam mineral, naungan vegetasi. Berdasarkan hasil penelitian yang telah dilakukan maka telah di dapatkan kriteria pengasuhan gajah jinak di lingkungan domestikasi yang sudah tervalidasi oleh pemerhati gajah dan hasil evaluasi praktek pengasuhan gajah di TNWK (PKG dan ERU).

\section{A. Kriteria Syarat-Syarat Lingkungan Untuk Domestikasi Gajah Sumatera (Elephas maximus sumatranus)}

Hasil penelitian dari beberapa studi pustaka telah diperoleh suatu kriteria pengasuhan gajah sumatera jinak di lingkungan domestikasi final yang sudah divalidasi oleh pemerhati gajah yang disajikan pada Tabel 1. Validasi kriteria pengasuhan gajah jinak di lingkungan domestikasi dilakukan oleh pemerhati gajah yaitu ketua mahout Indonesia dan sekertaris Forum Konservasi Gajah Indonesia (FKGI), dokter hewan dari WWF Indonesia Bukit Barisan Selatan Conservation Program, dan 2 orang mahout di Taman Safari Bogor. 
Tabel 1. Kriteria pengasuhan gajah Sumatera (Elephas maximus sumatranus) jinak di lingkungan domestikasi.

\begin{tabular}{|c|c|c|c|c|c|}
\hline $\begin{array}{l}\text { (A) } \\
\text { No. }\end{array}$ & $\begin{array}{c}\text { (B) } \\
\text { Faktor }\end{array}$ & $\begin{array}{c}(\mathrm{C}) \\
\text { Sesuai }\end{array}$ & $\begin{array}{c}\text { (D) } \\
\text { Kurang sesuai }\end{array}$ & $\begin{array}{c}\text { (E) } \\
\text { Tidak sesuai }\end{array}$ & $\begin{array}{c}(\mathbf{F}) \\
\text { Sumber }\end{array}$ \\
\hline 1. & $\begin{array}{l}\text { Populasi } \\
\text { Berkelompok }\end{array}$ & $20-35$ ekor. & $\begin{array}{l}15-20 \text { ekor atau } \\
35-43 \text { ekor. }\end{array}$ & $\begin{array}{l}<15 \text { ekor atau } \\
>43 \text { ekor. }\end{array}$ & $\begin{array}{l}\text { Shoshani dan } \\
\text { Eisenberg, } \\
1982 .\end{array}$ \\
\hline 2. & Home range & 32,4--166,9 km²/hari. & $\begin{array}{l}24,3-32,4 \\
\mathrm{~km}^{2} / \text { hari atau } \\
166,9-208,62 \\
\mathrm{~km}^{2} / \text { hari. }\end{array}$ & $\begin{array}{l}<24,3 \mathrm{~km}^{2} / \text { hari } \\
\text { atau }>208,62 \\
\mathrm{~km}^{2} / \text { hari. }\end{array}$ & $\begin{array}{l}\text { Shoshani dan } \\
\text { Eisenberg, } \\
1982 . .\end{array}$ \\
\hline 3. & $\begin{array}{l}\text { Makan } \\
\text { (10\% dari berat } \\
\text { badan) }\end{array}$ & $\begin{array}{l}200-300 \mathrm{~kg} / \text { hari dan } \\
70 \text { jenis tumbuhan. }\end{array}$ & $\begin{array}{l}150-200 \mathrm{~kg} / \mathrm{hari} \\
\text { atau } 300-375 \\
\mathrm{~kg} / \mathrm{hari} \text { dan } 52- \\
70 \text { jenis } \\
\text { tumbuhan. }\end{array}$ & $\begin{array}{l}<150 \mathrm{~kg} / \text { hari atau } \\
>375 \mathrm{~kg} / \text { hari. }<52 \\
\text { jenis tumbuhan } \\
\text { atau }>87 \text { jenis } \\
\text { tumbuhan. }\end{array}$ & $\begin{array}{l}\text { Shoshani dan } \\
\text { Eisenberg, } \\
1982 .\end{array}$ \\
\hline 4. & Air & $50-150$ liter/hari. & $\begin{array}{l}37,5-50 \\
\text { liter/hari atau } \\
150-187,5 \\
\text { liter/hari. }\end{array}$ & $\begin{array}{l}<37,5 \text { liter/hari } \\
\text { atau }>187,5 \\
\text { liter/hari. }\end{array}$ & $\begin{array}{l}\text { Shoshani dan } \\
\text { Eisenberg, } \\
1982 .\end{array}$ \\
\hline 5. & Naungan & $\begin{array}{l}\text { Tersedia vegetasi hutan } \\
\text { yang lebat untuk } \\
\text { membuat suhu } \\
\text { tubuhnya stabil. }\end{array}$ & $\begin{array}{l}\text { Tersedia vegetasi } \\
\text { hutan yang cukup } \\
\text { untuk membuat } \\
\text { suhu tubuhnya } \\
\text { stabil. }\end{array}$ & $\begin{array}{l}\text { Tidak tersedianya } \\
\text { vegetasi untuk } \\
\text { membuat suhu } \\
\text { tubuhnya stabil. }\end{array}$ & $\begin{array}{l}\text { Shoshani dan } \\
\text { Eisenberg, } \\
1982 .\end{array}$ \\
\hline 6. & Berkubang & $\begin{array}{l}\text { Mudah berkubang pada } \\
\text { pagi,siang dan sore hari } \\
\text { secara intensif. }\end{array}$ & $\begin{array}{l}\text { Berkubang pada } \\
\text { siang hari. }\end{array}$ & Tidak berkubang. & $\begin{array}{l}\text { Shoshani dan } \\
\text { Eisenberg, } \\
1982 .\end{array}$ \\
\hline 7. & Istirahat & 2 kali dalam sehari. & $\begin{array}{l}\text { > } 1 \text { kali dalam } \\
\text { sehari. }\end{array}$ & Tidak istirahat. & $\begin{array}{l}\text { Syamsuardi } \\
\text { dkk, } 2010 .\end{array}$ \\
\hline 8. & $\begin{array}{l}\text { Pengembalaan } \\
\text { gajah }\end{array}$ & $6-7$ jam. & $\begin{array}{l}4,5-6 \text { jam atau } \\
7-8,75 \text { jam. }\end{array}$ & $\begin{array}{l}<4,5 \text { jam atau }> \\
8,75 \text { jam. }\end{array}$ & $\begin{array}{l}\text { Syamsuardi } \\
\text { dkk, } 2010 .\end{array}$ \\
\hline 9. & $\begin{array}{l}\text { Pakan tambahan } \\
\text { (suplemen) }\end{array}$ & $\begin{array}{l}1-2 \text { kali dalam } 2 \\
\text { minggu. }\end{array}$ & $\begin{array}{l}\text { >2 kali dalam } \\
\text { seminggu. }\end{array}$ & $\begin{array}{l}\text { Tidak ada pakan } \\
\text { tambahan } \\
\text { (suplemen). }\end{array}$ & $\begin{array}{l}\text { Syamsuardi } \\
\text { dkk, } 2010 .\end{array}$ \\
\hline 10. & Gajah mandi & $2-3 \mathrm{kali} / \mathrm{hari}$. & $\begin{array}{l}<2 \mathrm{kali} / \mathrm{hari} \text { atau } \\
>3 \mathrm{kali} / \mathrm{hari} \text {. }\end{array}$ & $\begin{array}{l}\text { Gajah tidak } \\
\text { mandi. }\end{array}$ & $\begin{array}{l}\text { Syamsuardi } \\
\text { dkk, } 2010 .\end{array}$ \\
\hline 11. & $\begin{array}{l}\text { Pemeriksaan } \\
\text { secara medis }\end{array}$ & $2-3$ kali/tahun. & $\begin{array}{l}<2 \mathrm{kali} / \text { tahun atau } \\
>3 \mathrm{kali} / \text { tahun } .\end{array}$ & $\begin{array}{l}\text { Tidak ada } \\
\text { pemeriksaan } \\
\text { secara medis. }\end{array}$ & $\begin{array}{l}\text { Syamsuardi } \\
\text { dkk, } 2010 .\end{array}$ \\
\hline 12. & $\begin{array}{l}\text { Pemeriksaan } \\
\text { sampel darah }\end{array}$ & $1-2$ kali/tahun. & $>2 \mathrm{kali} /$ tahun. & $\begin{array}{l}\text { Tidak ada } \\
\text { pemeriksaan } \\
\text { sampel darah. }\end{array}$ & $\begin{array}{l}\text { Syamsuardi } \\
\text { dkk, } 2010 .\end{array}$ \\
\hline 13. & $\begin{array}{l}\text { Perawatan gajah } \\
\text { sakit }\end{array}$ & $\begin{array}{l}\text { Gajah sakit berada } \\
\text { dicamp khusus, isolasi } \\
\text { gajah, pengawasan } \\
\text { dokter, pemberian } \\
\text { obat-obatan hanya } \\
\text { dilakukan oleh dokter } \\
\text { hewan, segala tindakan } \\
\text { gajah sakit harus seizin } \\
\text { dokter, pemberian } \\
\text { pakan dan minum } \\
\text { secara rutin, } \\
\text { penanganan darurat } \\
\text { khusus secara cepat. }\end{array}$ & $\begin{array}{l}\text { Kurangnya } \\
\text { penanganan medis } \\
\text { dari mahout dan } \\
\text { tim medis. }\end{array}$ & $\begin{array}{l}\text { Tidak ada } \\
\text { penangan gajah } \\
\text { sakit secara } \\
\text { medis. }\end{array}$ & $\begin{array}{l}\text { Syamsuardi } \\
\text { dkk, 2010. }\end{array}$ \\
\hline
\end{tabular}


Tabel 1 (lanjutan)

\begin{tabular}{|c|c|c|c|c|c|}
\hline (A) & (B) & $(\mathbf{C})$ & (D) & $(\mathbf{E})$ & (F) \\
\hline 14. & $\begin{array}{l}\text { Perawatan gajah } \\
\text { birahi }\end{array}$ & $\begin{array}{l}\text { Pengasingan gajah, dekatkan } \\
\text { dengan gajah jinak yang } \\
\text { disukai, jangan berikan } \\
\text { suplemen, kurangi porsi makan, } \\
\text { dekatkan dengan sumber air dan } \\
\text { teduh, memanggil nama } \\
\text { sebelum mendekati agar tidak } \\
\text { kaget, jangan memindahkan } \\
\text { gajah sebelum diketahui reaksi } \\
\text { gajah terhadap mahout, jangan } \\
\text { membuka rantai gajah dan harus } \\
\text { dalam kondisi di borgol. }\end{array}$ & $\begin{array}{l}\text { Kurangnya } \\
\text { penanganan } \\
\text { secara khusus } \\
\text { dari mahout. }\end{array}$ & $\begin{array}{l}\text { Tidak ada } \\
\text { penanganan } \\
\text { secara khusus. }\end{array}$ & $\begin{array}{l}\text { Syamsuardi } \\
\text { dkk, } 2010 .\end{array}$ \\
\hline 15. & $\begin{array}{l}\text { Penanganan } \\
\text { gajah betina } \\
\text { hamil }\end{array}$ & $\begin{array}{l}\text { Perhatian intensif dari mahout, } \\
\text { pakan yang memadai, } \\
\text { pemeriksaan sebulan sekali oleh } \\
\text { dokter hewan dan melakukan } \\
\text { monitoring sampai gajah } \\
\text { melahirkan. }\end{array}$ & $\begin{array}{l}\text { Kurangnya } \\
\text { penanganan dan } \\
\text { perhatian yang } \\
\text { lebih intensif } \\
\text { dari mahout dan } \\
\text { tim medis. }\end{array}$ & $\begin{array}{l}\text { Tidak ada } \\
\text { penanganan } \\
\text { dan perhatian } \\
\text { secara khusus. }\end{array}$ & $\begin{array}{l}\text { Syamsuardi } \\
\text { dkk, } 2010 .\end{array}$ \\
\hline 16. & $\begin{array}{l}\text { Perawatan anak } \\
\text { gajah }\end{array}$ & $\begin{array}{l}\text { Diajar dasar tingkah laku dan } \\
\text { latihan awal dimulai segera } \\
\text { setelah lahir, latihan formal } \\
\text { tingkah laku secara kontinu } \\
\text { antar umur } 3 \text { bulan sampai } 2 \\
\text { tahun, gunakan tali pengendali } \\
\text { yang besar dan lembut untuk } \\
\text { mengurangi lecet, penyapihan } \\
\text { sampai minimal } 2 \text { tahun. }\end{array}$ & $\begin{array}{l}\text { Kurangnya } \\
\text { penanganan } \\
\text { perawatan anak } \\
\text { gajah oleh } \\
\text { mahout. }\end{array}$ & $\begin{array}{l}\text { Tidak ada } \\
\text { perawatan } \\
\text { anak gajah } \\
\text { dari lahir. }\end{array}$ & $\begin{array}{l}\text { Syamsuardi } \\
\text { dkk, } 2010 .\end{array}$ \\
\hline 17. & $\begin{array}{l}\text { Peralatan } \\
\text { mahout }\end{array}$ & $\begin{array}{l}\text { Gancu, sepatu, topi, baju } \\
\text { seragam, tas ransel, parang, } \\
\text { matras, verpes (botol air } \\
\text { minum), dan jas hujan. }\end{array}$ & $\begin{array}{l}\text { Gancu, } \\
\text { sepatu,topi, baju } \\
\text { seragam kerja. }\end{array}$ & $\begin{array}{l}\text { Tidak ada } \\
\text { peralatan yang } \\
\text { digunakan. }\end{array}$ & $\begin{array}{l}\text { Syamsuardi } \\
\text { dkk, } 2010 .\end{array}$ \\
\hline
\end{tabular}

Sumber: Data sekunder yang diolah (2013).

Berdasarkan validasi dari pemerhati gajah terdapat 17 variabel kriteria pengasuhan gajah jinak dilingkungan domestikasi. Namun mengalami sedikit perubahan dari kriteria yang telah dibuat, dari setiap pendapat yang diajukan oleh setiap pemerhati gajah akan ditarik dalam satu kesimpulan. Perbedaan pendapat dalam validasi kriteria pengasuhan gajah jinak di lingkungan domestikasi berasal dari ketua mahout Indonesia dan sekertaris FKGI, yang menyebutkan bahwa gajah Sumatera sangat membutuhkan banyak air. Sehingga dari kriteria awal yang menyebutkan bahwa gajah Sumatera memerlukan air minum 20 -- 50 liter/hari berubah menjadi 50--150 liter/hari karena gajah sangat bergantung dengan air untuk kehidupan sehari-hari. Hal ini juga dapat dilihat dari perubahan waktu mandi gajah yaitu dari kriteria awal gajah mandi 1--2 kali/hari berubah menjadi 2--3 kali/hari.

Menurut Mahanani (2012) Ketersediaan air bagi satwa merupakan faktor utama dalam kelangsungan hidupnya. Gajah merupakan satwa yang memerlukan banyak air untuk keperluan minum, berkubang, sarana hubungan sosial dengan kawanannya. Bila dikaji dari aspek ketergantungannya terhadap air, maka gajah termasuk golongan satwa water dependent species yaitu binatang yang memerlukan air untuk proses penghancuran makanan dan memperlancar proses pencernaan. 


\section{B. Evaluasi Praktek Pengasuhan Gajah Sumatera (Elephas maximus sumatranus)}

Pengasuhan gajah jinak sangat erat hubungannya dengan kesehatan gajah. Permasalahan pengasuhan gajah jinak yang tersulit diatasi adalah bila terjadi gangguan kesehatan akibat manajemen pengasuhan yang kurang maksimal sehingga gajah jinak mendapatkan pasokan nutrisi yang kurang dalam jangka waktu yang lama sehingga pada akhirnya menyebabkan malnutrisi. Hal ini biasanya sangat erat hubungannya dengan cara pengasuhan sehari-hari dan perhatian terhadap pemenuhan kebutuhan yang berhubungan dengan perilaku alaminya. Keduanya sangat berhubungan erat, salah satu tak terpenuhi akan berpengaruh terhadap kondisi lainnya (Masabine, 2013).

Gajah Sumatera merupakan satwa langka liar yang dilindungi. Agar bisa hidup berdampingan dengan manusia dan mendapat pengasuhan dari manusia maka gajah Sumatera harus didomestikasi. Kriteria pengasuhan gajah jinak di lingkungan domestikasi harus memenuhi standar. Evaluasi praktek pengasuhan gajah jinak dilakukan di Taman Nasional Way Kambas yaitu: PKG dan ERU.

\section{Pusat Konservasi Gajah (PKG)}

Tabel 2. Nilai praktek pengasuhan gajah Sumatera (Elephas maximus sumatranus) jinak di lingkungan domestikasi Pusat Konservasi Gajah.

\begin{tabular}{llcccc}
\hline No. & \multicolumn{1}{c}{ Faktor } & Sesuai & Kurang Sesuai & Tidak Sesuai & Nilai \\
\hline 1. & Populasi berkelompok & & & $\sqrt{ }$ & 1 \\
2. & Home range & & & 1 \\
3. & Makan (10\% dari berat badan) & $\sqrt{ }$ & $\sqrt{ }$ & 3 \\
4. & Air & $\sqrt{ }$ & & 3 \\
5. & Naungan & $\sqrt{ }$ & & & 1 \\
6. & Berkubang & & & 3 \\
7. & Istirahat & $\sqrt{ }$ & & 3 \\
8. & Pengembalaan gajah & $\sqrt{ }$ & & 3 \\
9. & Pakan tambahan & & & 3 \\
10. & Gajah mandi & $\sqrt{ }$ & & 3 \\
11. & Pemeriksaan secara medis & $\sqrt{ }$ & & 3 \\
12. & Pemeriksaan sampel darah & $\sqrt{ }$ & & 3 \\
13. & Perawatan gajah sakit & $\sqrt{ }$ & & 3 \\
14. & Perawatan gajah birahi & $\sqrt{ }$ & & 3 \\
15. & Penanganan gajah betina hamil & $\sqrt{ }$ & & \\
16. & Perawatan anak gajah & $\sqrt{ }$ & & \\
17. & Peralatan mahout & & & \\
\hline \multicolumn{2}{l}{} & Total & & \\
\hline
\end{tabular}

Sumber : Hasil penelitian (2013).

Berdasarkan Tabel 2 diperoleh skor 43, hal ini menunjukkan bahwa secara keseluruhan tingkat praktek pengasuhan gajah jinak di PKG menunjukkan hasil yang sesuai. Namun terdapat beberapa variabel pengasuhan yang belum memenuhi kriteria sesuai yaitu populasi, home range dan naungan. Populasi dikatakan tidak sesuai karena jumlah gajah jinak di PKG sedikit dan setiap gajah jinak yang berada di PKG sudah mendapatkan pengasuhan dari mahout. Dengan demikian intensitas gajah jinak satu dengan yang lainnya sedikit berkurang karena pergerakan populasi gajah sudah ditentukan oleh mahout.

Menurut WWF (2005), jumlah anggota satu kelompok gajah Sumatera berkisar 20--35 ekor, atau berkisar 2--23 ekor. Setiap kelompok gajah Sumatera dipimpin oleh induk betina yang paling besar, sementara yang jantan dewasa hanya tinggal pada periode tertentu untuk kawin dengan beberapa betina pada kelompok tersebut. 
Dari hasil penelitian dilapangan Home range gajah jinak dikatakan tidak sesuai karena gajah jinak hanya memiliki daerah jelajah di sekitar PKG dan setiap harinya gajah jinak hanya menempuh 2-3 km 2 /hari sedangkan menurut Shoshani dan Eisenberg (1982) home range gajah setiap harinya 32,4--166,9 $\mathrm{km}^{2} /$ hari. Home range gajah sangat mempengaruhi produktivitas makannya karane gajah selalu berjalan untuk mencari makanan, tidak semua makanan yang ia temui dimakan dan dihabiskan, sesekali gajah akan berhenti untuk mengambil makanan yang disukai (Santoso, 2011). Menurut penelitian Syarifuddin (2008) secara alamiah gajah membutuhkan areal yang luas untuk mencari makan dan memenuhi kebutuhan hidupnya sehingga diharapkan home range gajah jinak ditambah agar dapat memberikan sirkulasi darah yang baik dan gajah jinak akan lebih banyak mendapatkan variasi makanan.

Dari hasil penelitian menunjukkan bahwa kondisi naungan di PKG tidak sesuai karena kondisi tutupan lahan tidak sesuai dengan naungan untuk gajah jinak dan tidak memiliki vegetasi hutan yang lebat dan kurang begitu cukup untuk keberadaan gajah jinak. Vegetasi jenis pohon sudah jarang ditemukan dan hanya terlihat hamparan lahan luas dengan sejumlah tumbuhan. Kandang gajah jinak di PKG berada di alam terbuka yang hanya terdapat patok-patok yang bediri sekitar setengah meter yang digunakan untuk mengikat gajah jinak. Sedangkan menurut hasil penelitian Abdullah (2012), gajah memerlukan tempat-tempat yang memiliki penutupan tajuk yang baik sebagai tempat berlindung sebab gajah tidak tahan terhadap panas matahari.

Menurut penelitian Mahanani (2012), struktur vegetasi hutan merupakan salah satu faktor pembentuk naungan bagi satwa liar yang berfungsi sebagai tempat persembunyian, tempat istirahat, tempat berlindung dan penyesuaiaan terhadap perubahan temperatur. Gajah merupakan satwa liar yang termasuk berdarah panas, memerlukan kondisi temperatur tubuh yang sesuai dengan temperatur lingkungannya. Hal ini juga berkaitan dengan hasil penelitian Syarifuddin (2008) yang menyatakan selain untuk mengurangi panas di tubuhnya biasanya dia berkubang dalam lumpur. Setelah berkubang, aktivitas berikutnya adalah menggosokgosokkan badannya di batang pohon untuk mengurangi rasa gatal di tubuhnya. Pohon-pohon yang dipakai untuk menggosok badannya (rubbing trees) akan terlihat jelas karena ada bekas lumpur yang menempel di tempat tertentu, yang biasanya cukup tinggi sesuai dengan tinggi gajah.

Peralatan mahout dan waktu istirahat gajah di PKG menunjukan hasil yang kurang sesuai dimana waktu istirahat gajah jinak hanya dilakukan sekali dalam sehari. Peralatan mahout yang dimiliki kurang memenuhi standar yang sesuai dengan kriteria sehingga berdampak dalam praktek pengasuhan gajah jinak.

\section{Elephant Respon Unit (ERU)}

Secara umum pengasuhan gajah jinak di ERU terjadi secara alami. Dari hasil penelitian terdapat beberapa faktor yang tidak sesuai sama hal nya dengan yang di PKG yaitu home range gajah jinak karena tidak mencapai standar kriteria yang sudah ditentukan. Untuk skor 0 dikarenakan variabel kriteria tidak terdapat di ERU, karena ERU hanya memiliki jumlah gajah jinak jantan 2 ekor.

Hasil penelitian menunjukkan skor 40, hal ini menunjukkan bahwa praktek pengasuhan gajah Sumatera jinak di ERU sudah sesuai. Hasil penelitian evaluasi praktek pengasuhan gajah jinak di ERU dapat di lihat di tabel 3. 
Tabel 3. Nilai pengasuhan gajah Sumatera (Elephas maximus sumatranus) jinak di lingkungan domestikasi Elphant Respon Unit.

\begin{tabular}{|c|c|c|c|c|c|}
\hline No. & Faktor & Sesuai & Kurang Sesuai & Tidak Sesuai & Nilai \\
\hline 1. & Populasi berkelompok & & & & 0 \\
\hline 2. & Home range & & & $\sqrt{ }$ & 1 \\
\hline 3. & Makan (10\% dari berat badan) & $\sqrt{ }$ & & & 3 \\
\hline 4. & Air & $\sqrt{ }$ & & & 3 \\
\hline 5. & Naungan & $\sqrt{ }$ & & & 3 \\
\hline 6. & Berkubang & $\sqrt{ }$ & & & 3 \\
\hline 7. & Istirahat & $\sqrt{ }$ & & & 3 \\
\hline 8. & Pengembalaan gajah & $\sqrt{ }$ & & & 3 \\
\hline 9. & Pakan tambahan & $\sqrt{ }$ & & & 3 \\
\hline 10. & Gajah mandi & $\sqrt{ }$ & & & 3 \\
\hline 11. & Pemeriksaan secara medis & $\sqrt{ }$ & & & 3 \\
\hline 12. & Pemeriksaan sampel darah & $\sqrt{ }$ & & & 3 \\
\hline 13. & Perawatan gajah sakit & $\sqrt{ }$ & & & 3 \\
\hline 14. & Perawatan gajah birahi & $\sqrt{ }$ & & & 3 \\
\hline 15. & Penanganan gajah betina hamil & & & & 0 \\
\hline 16. & Perawatan anak gajah & & & & 0 \\
\hline \multirow[t]{2}{*}{17.} & Peralatan mahout & $\sqrt{ }$ & & & 3 \\
\hline & & Total & & & 40 \\
\hline
\end{tabular}

Sumber : Hasil penelitian (2013).

Secara keseluruhan praktek pengasuhan gajah sudah sesuai dengan kriteria pengasuhan gajah Sumatera jinak dilingkungan domestikasi, namun dalam pelaksanaanya masih mengalami sedikit kekurangan seperti peralatan dan home range yang belum memenuhi standar yang sudah dibuat. Dari dua unit pengasuhan gajah jinak di TNWK semua memiliki cara sendiri dalam pengasuhan gajah jinak.

\section{KESIMPULAN DAN SARAN}

\section{Kesimpulan}

Berdasarkan penelitian yang telah dilakukan, diperoleh kesimpulan sebagai berikut:

1. Telah diperoleh susunan kriteria yang dapat digunakan sebagai rubrik penilaian dalam domestikasi gajah Sumatera yang dipandang valid oleh para pemerhati gajah, meliputi variabel: populasi berkelompok, home range, makan, air, naungan, berkubang, istirahat, penggembalaan gajah, pakan tambahan, gajah mandi, pemeriksaan secara medis, pemeriksaan sampel darah, perawatan gajah sakit, perawatan gajah birahi, penanganan gajah betina hamil, perawatan anak gajah dan peralatan mahout.

2. Praktek pengasuhan Pusat Konservasi Gajah (PKG) menunjukkan hasil yang sesuai dengan (skor 43). Ada beberapa variabel yang kurang sesuai yaitu waktu istirahat dan peralatan mahout. Populasi berkelompok, home range dan naungan termasuk kedalam kategori tidak sesuai.

3. Praktek pengasuhan gajah jinak di Elephant Respon Unit (ERU) menunjukkan skor 40 yang berarti praktek pengasuhan gajah jinak secara umum sudah termasuk dalam kategori sesuai, namun ada variabel yang tidak sesuai yaitu home range.

\section{Saran}

Sebaiknya untuk meningkatkan relevansi kriteria yang sudah dihasilkan maka perlu penelitian lebih lanjut dengan melakukan validasi ilmiah lain yang kompeten. Dan hasil kriteria pengasuhan gajah Sumatera jinak dapat diterapkan di lembaga domestikasi 
pengasuhan gajah jinak lainnya yang memilki kondisi lingkungan yang sama seperti di Pusat Konservasi Gajah dan Elephant Respon Unit Taman Nasional Way Kambas.

\section{DAFTAR PUSTAKA}

Abdullah, Asiah, dan T. Japisa. 2012. Karakteristik habitat gajah sumatera (Elephas maximus sumatranus) di kawasan ekosistem Seulawah Kabupaten Aceh Besar. Jurnal Ilmiah Pendidikan Biologi. Biologi Edukasi 4(1): 41--45.

Alikodra, H.S. 2002. Pengelolaan Satwa Liar jilid 1. Penerbit IPB Press, Bogor. - 2010. Teknik Pengelolaan Satwa Liar dalam Rangka Mempertahankan Keanekaragaman Hayati Indonesia. Penerbit IPB Press, Bogor.

CITES. 2000. Appendix 1, as adopted by the conference of the parties. Diakses 15 November 2013. Pukul 15.30 WIB. Sumber http://www. cites.org/eng/ append/ III. html.

Firqan, I. 2012. Melirik peran dan daya guna taman konservasi Lampung. Diakses: 23 November 2012. Pukul 11:05 WIB. Sumber. http:// astacala. org/wp/2012/03/melirik-peran-dan-dayaguna-taman-konservasi-gajah-di-lampung/.

Mahanani, A.I. 2012. Strategi konservasi gajah sumatera (elephas maximus sumatranus) di suaka margasatwa Padang Pesugihan Provinsi Sumatera Selatan berdasarkan daya dukung habitat. Tesis. Universitas Diponegoro. Semarang.

Musabine, E. S. 2013. Malnutrisi pada gajah sumatera (spending my time on this weekend to treat elephant). Diakses 29 juni 2013. Pukul 15:15 WIB. Sumber. http: //ernisuyanti medic konservasi. blogspot. Com /2013/05/ spending-my-time-on-this-weekend-to. html.

Nababan, H. 2007. Mengawal lingkungan Lampung (2-Habis): Senthong, buruknya nasib gajah (Kompas, 28 Maret 2007). Diakses. 2 Desember 2012. Pukul. 01:13 WIB. Sumber. http:// ulunlampung .blogspot.com /2007/03/ mengawal lingkungan lampung 2 habis. html.

Nasution, S. 2012. Metode Research (Penelitian Ilmah). Bumi Aksara. Jakarta.

Santoso, Y ddk. 2011. Preferensi dan pendugaan produktivitas pakan alami populasi gajah sumatera (Elephasmaximus sumatranus Temmick,1847) di hutan produksi khusus (hpkh) pusat latihan gajah (PLG) sebelat, Bengkulu utara. Jurnal. Medta Konservasl VoL 15, No. 3 Desember $2011: 149$ - 155.

Shoshani, J, dan Eisenberg,J.F, 1982. Elephas Maximus. The American Society of Mammalogists.

Sugiyono. 2009. Metode Penelitian Kuantitatif Kualitatif dan $R \& D$. alfabeta. Bandung.

Syamsuardi., W. Sukmantoro., Muslino., Nukman., N. Fadhli., A. Purwaka., Riyadin., E. Heri., dan J. Prawoto. 2010. Standar operasional prosedur puntuk elephant flying squad dalam mitigasi konflik manusia dan gajah. WWF Indonesia.

Syafruddin. 2010. Teknik delphi dalam penelitian. Diakses 15 April 2013. Pukul 22:30 WIB. Sumber. http://teomokole.blogspot.com/2010/10/teknik-delphi-dalam-penelitian.html.

Syarifuddin, H. 2008. Analisis daya dukung habitat dan permodelan dinamika populasi gajah sumatera (Elephas maximus sumatranus) studi kasus di kawasan Seblat Kabupaten Bengkulu Utara. Disertasi. Institut Pertanian Bogor. Bogor.

Word Wildlife Found. 2005. Mengenal gajah Sumatera. Diakses 15 November 2013. Pukul 19.00 WIB. Sumber http://www.wwf.or.id/?5484/Mengenal-Gajah-Sumatra.

Yitnosumarno, S. 1994. Dasar-Dasar Statistika Dengan Penekanan Terapan Dalam Agrokompleks. Teknologi dan Sosial. Buku. Raja Grafindo Persada. Jakarta. 